\title{
АПК РОССИИ НА ПРИМЕРЕ КЛАСТЕРОВ АГРОПРОДОВОЛЬСТВЕННОГО КОМПЛЕКСА В АСПЕКТЕ ЭКСПОРТА ПРОДУКЦИИ
}

\section{AGRO-INDUSTRIAL COMPLEX OF RUSSIA ON THE EXAMPLE OF AGRI-FOOD COMPLEX CLUSTERS IN THE ASPECT OF PRODUCT EXPORT}

Yu. Mindlin

Summary. In today's increasingly globalized international markets, it is increasingly difficult for individual companies to obtain and discount competitive advantages. In addition to the competition and competitiveness of markets, it is also important to interact with various actors that have an impact on the final effects of competing companies, and, as a result, the results of competition between national economies. In this light, in the search for ways to maintain and, especially, increase the competitiveness of the national agricultural sector, it is worth paying attention to the opportunities that can be created in this regard by supporting the development of export-oriented business clusters within the framework of state intervention. Assuming that strong export clusters have a positive impact on the competitiveness of industries and sectors, it should be borne in mind that actions to support their development should follow from an objective, thorough assessment of the presented noneconomic potential associated with the degree of business concentration. These measures should be implemented within the framework of wellthought-out strategies that reflect economic policies aimed at creating high international competitiveness of individual sectors of the economy.

The purpose of the article is to study the current state of the Russian agroindustrial complex on the example of agri-food complex clusters in the aspect of product export. The construction of these models was preceded by a critical analysis of the main aspects of the typology of business clusters and an attempt to determine the relationship between the emergence of clusters and innovations in industries and sectors.

Keywords: agricultural sector, clusters, competitiveness, modernization, export.

\author{
Миндлин Юрий Борисович \\ К.э.н., дочент, ФГБОУ ВО «Московская \\ государственная академия ветеринарной медицины \\ и биотехнологии имени К.И. Скрябина» \\ mindliny@mail.ru
}

Аннотация. На современных, все более глобализирующихся международных рынках получение и дисконтирование конкурентных преимуществ отдельными компаниями становится все более трудным. Помимо соперничества и конкурентоспособности рынков, важным оказывается также, взаимодействие различных субъектов, имеющих влияние на конечные эффекты деятельности конкурирующих компаний, и, как следствие, результаты конкуренции национальных экономик. В свете этого, в поиске способов поддержания и, особенно, роста, конкурентоспособности национального сельскохозяйственного сектора, стоит обратить внимание на возможности, которые может создать в этом отношении поддержка в рамках государственного вмешательства развития бизнес-кластеров, ориентированных на экспорт. Приняв предположение, что сильные кластеры-экспортеры, благоприятно влияют на конкурентоспособность отраслей и секторов, необходимо иметь в виду, что действия по поддержке их развития должны вытекать из объективной, тщательной оценки, представленного не экономического потенциала, связанного со степенью концентрации бизнеса. Реализация этих мер должна осуществляться в рамках реализации продуманных стратегий, отражающих экономическую политику, ориентированную на формирование высокой международной конкурентоспособности отдельных секторов экономики.

Цель статьи — изучить современное состояние АПК России на примере кластеров агропродовольственного комплекса в аспекте экспорта продукции. Построению этих моделей предшествовал критический анализ основных аспектов типологии бизнес-кластеров, и попытка определить взаимосвязь между возникновением кластеров и инновациями отраслей и секторов.

Ключевые слова: сельскохозяйственный сектор, кластеры, конкурентоспособность, модернизация, экспорт.

гии развития таких кластеров должны основываться на моделировании их структур с особым вниманием к ключевым звеньям цепочки создания стоимости. Отправной точкой для их формулировки является правильное понимание понятия кластер, а основой их эффективного внедрения, например, в рамках кластерной политики, является практическая оперативность этого понятия. 
Кластеры можно рассматривать как минимум в трех разных понятиях. Первое из них имеет общий, концептуальный характер, что кластер - это: географическая концентрация взаимосвязанных компаний, специализированных поставщиков, подразделений, предоставляющих услуги, фирм, работающих в родственных секторах и связанных с ними учреждений (например, университетов, агентств по стандартизации и технических ассоциаций), представляющих указанные отрасли, конкурирующих между собой, но также сотрудничающих $[1,2,3,4]$. Однако этого понятия недостаточно для определения кластеров и их потенциала развития, таким образом, недостаточно объективно. Гораздо большие возможности в этом отношении создает второе понятие, имеющее аналитический характер, основанное на оценке степени концентрации занятости или числа субъектов и картографировании. Его важным элементом является также анализ конкурентных и кооперативных отношений (напр. характера кластерных инициатив и их роли в этом отношении) [5]. В третьем плане кластер можно понимать как модельную конструкцию, отражением которой является карта кластера и структура цепочки создания стоимости [6]. Именно эта картина дает возможность практически оперировать понятием кластер и строить на этой основе стратегии развития конкретных, аналитически идентифицированных кластеров. Следовательно, это позволяет основывать возможную кластерную политику на рациональных предпосылках и, таким образом, создавать возможность эффективной реализации.

Сейчас экспорт продовольственных товаров для России дороже, чем поставки оружия. В 2019 году страна принесла стране около 25 миллиардов долларов. На российские поля приходится $10-13 \%$ мирового экспорта зерна и 20-23\% мирового экспорта пшеницы. Тем не менее, из-за того, что пищевая промышленность остается сильно недоразвитой, Россия вынуждена импортировать большую часть своих рафинированных продуктов питания.

Сейчас Россия стоит перед важным стратегическим выбором. В свете потенциальных возможностей для роста, а также определенных внешних факторов, которые, как ожидается, повлияют на мировую сельскохозяйственную отрасль в ближайшие годы, будет ли она сосредоточена на использовании большего количества земель для выращивания сельскохозяйственных культур и, как следствие, увеличении своего экспорта и станет важной частью глобальной сельскохозяйственной цепочки - или она будет работать над улучшением своей пищевой промышленности, чтобы стать более независимой от мировых сельскохозяйственных животных? Одно можно сказать наверняка: от российского агропромышленного комплекса следует ожидать некоторых важных решений и развития.
Россия, с ее обширной территорией, прошла через ряд колебаний в течение 19-го и 20-го века. Несмотря на то, что в то время у нее было больше населения, чем в остальной Европе, большинство из которых проживало в сельских сельскохозяйственных общинах, Россия не могла конкурировать с точки зрения своего промышленного и экономического развития. Тем не менее, в то время как ее европейские соседи и Вольное экономическое общество стремились улучшить свои методы ведения сельского хозяйства, России удалось стать одним из крупнейших экспортеров сельскохозяйственных культур, особенно пшеницы (36\% от общего экспорта в 1910 году), несмотря на ее неэффективность в сельском хозяйстве.

Позднее освобождение царя Александра II о крепостных в середине 19-го века, как следствие Великой Сибирской миграции и сельского хозяйства, ориентированных на столыпинские реформы, открыло возможность для возделываемых расширения. Однако социально-политические потрясения, последовавшие вскоре после этого (Первая мировая война, большевистская революция, Гражданская война, а затем Вторая мировая война), не позволили российскому сельскохозяйственному сектору воспользоваться этой возможностью [8].

Когда в 1950-е годы ситуация стала более стабильной, советское правительство начало кампанию «Целинные земли». В последующее десятилетие только в азиатской части России было вспахано 13,6 млн. га земель, что продемонстрировало огромный потенциал страны с точки зрения сельскохозяйственного производства. Тем не менее, за углом был еще один переломный момент, который вот-вот должен был поколебать эту позитивную тенденцию - распад Советского Союза в 1991 году и распад государственно-командной экономики. Впоследствии, в 1990-х годах, большая часть пахотных земель и управляемых пастбищ была заброшена. Посевные площади и поголовье скота не восстановились до уровней до 1991 года [7].

За последние два десятилетия сельское хозяйство России претерпело интенсивную модернизацию. Это было подкреплено развивающимися макроэкономическими факторами, среди которых создание кластеров, усиление интеграции в международную торговлю, расширение передачи технологий и иностранных инвестиций в сельское хозяйство, а также необходимость повышения безопасности и эффективности производства.

Разработка технического оборудования сельскохозяйственных кластеров находилась на переднем крае процесса модернизации, поскольку напрямую влияла на объем производства, а также на эффективность задействованного человеческого капитала. Например, 
в 2014 году в рамках государственного проекта по повышению производительности сельского хозяйства в стране сельскохозяйственным производителям были предложены субсидии в размере $15 \%$ для приобретения необходимого технического оборудования. Это расширится в 2017 году, когда общая стоимость Госпрограммы увеличится на 2,6\% процента [13].

Второй основной опорой процесса модернизации сельскохозяйственных кластеров было принятие новой политики, более подходящей для развивающейся промышленности и эпохи глобализации. Растущие опасения по поводу зависимости от импорта в конце 2000-х годов побудили сосредоточить политику на стимулировании внутренних поставок продовольствия. Государственная поддержка была оценена ОЭСР как оценка поддержки производителей в 22\% в 2008-2010 годах, что было выше уровня поддержки, предоставленной в ЕС. Хотя такое ужесточение государственной помощи было связано, среди прочего, с глобальным экономическим кризисом в 2009 году, а также с местной засухой, оно также означает долгосрочную ориентацию в пользу роста производства и импортозамещения.

Тем не менее, в российском аграрном секторе по-прежнему наблюдались недостатки, которые не устранялись. В частности, учитывая объем земельных ресурсов в России, ее сельскохозяйственный сектор, как никакое другое место, требует развитой инфраструктуры услуг и транспорта. Более того, общественные системы управления водными и земельными ресурсами также важны для эффективности сельскохозяйственного производства. Однако недостаточный уровень инвестиций, НИОКР и инноваций приводит к тому, что Россия отстает на мировой арене.

В то время как вхождение в глобальную сельскохозяйственную экономику предполагало расширение передачи технологий и иностранных инвестиций в сельское хозяйство, Россия начала импортировать семена, домашний скот и западную сельскохозяйственную технику. Хотя этот импорт открывал новые рыночные возможности, можно было ожидать, что производители отреагируют на них с целью повышения эффективности своей деятельности.

Импорт гибридных семян кукурузы с Запада (в основном из Франции и Венгрии) на первый взгляд дал некоторые благоприятные результаты. С 2002 года российский импорт гибридных семян кукурузы увеличился на 84\% и достиг 36820 тонн в 2015 году, из которых 50\% было использовано для планирования в том же году согласно Атласу мировой торговли (2016). Урожайность кукурузы в России увеличилась почти на 50\% за тот же период и составила 4,93 тонны с гектара в 2015 году [11].
Однако такие семена стабильно обеспечивают ожидаемые однородные характеристики и высокую урожайность только во время первого сбора урожая. Таким образом, в то время как они могут внести значительный вклад в резкий рост объемов сельскохозяйственного производства, особенно во второй половине 20-го века, гибридные семена привести к увеличению зависимости от импорта семян, что делает их слабое долгосрочное решение с глобальной точки доминантности зрения.

Более того, существенная утрата агробиоразнообразия и повышенная восприимчивость к болезням и погодным условиям являются еще одним потенциальным глобальным последствием зависимости от импорта гибридных семян. В то время как цель фермы, в отличие от природных экосистем, заключается в производстве урожая, интенсификация сельского хозяйства и монокультурные системы ужезаметно снизили биоразнообразие на фермах. Это снижает долгосрочную устойчивость сельского хозяйства. Сохранение агробиоразнообразия обеспечивает важные экосистемные услуги и поэтому должно стать приоритетом в сельскохозяйственной отрасли. Фактически, российское правительство уже упомянуло об этом как об одном из основных направлений будущего развития сельского хозяйства страны.

Россия производит более пятой части мирового экспорта пшеницы, и президент Путин планирует и далее наращивать экспорт продовольствия в течение следующих четырех лет.

Конкурентные преимущества, возникающие благодаря кластерам,- это результат коллективных, скоординированных действий не только предприятий определенной отрасли, но и связанных с ними предприятий сопутствующих отраслей, а также организаций и учреждений поддержки. Таким образом, хорошо функционирующие кластеры способствуют формированию и распространению инноваций. Особая роль в этом отношении отводится экспортным кластерам, признанным экономическими структурами, являющимся наилучшим воплощением конкурентных преимуществ в условиях прогрессирующей глобализации рынков и усиливающейся международной конкуренции. Это связано с тем, что конечным испытанием инноваций и конкурентоспособности является противостояние на международных рынках [9].

Для агропродовольственного сектора мы уже несколько лет сталкиваемся с своеобразной экспансией экспорта с участием различных отраслей. Понятно, что не все отрасли промышленности предрасположены к достижению экспортных успехов, и в то же время все чаще поднимается вопрос о неизбежном таянии традиционных конкурентных преимуществ российского аг- 
ропродовольственного сектора. В этой ситуации развитие сильных кластеров агро-пищевых продуктов может способствовать укреплению существующих и созданию новых конкурентных преимуществ с глубокими возможностями, интеллектуальной специализации, снижению операционных издержек, созданию уникальных цепочек ценностей. Поддержка развития российских экспортеров кластеров агро-пищевых кажется разумным, особенно в свете того факта, что на фоне международных сравнений превратились они, пока что, как не очень сильные [9]. Это означает, что выдающиеся результаты экспорта до сих пор могут быть не только сохранены, но и улучшены.

Потенциал развития агропродовольственных кластеров в России разнообразен как в региональном, так и в отраслевом плане. Учитывая результаты проведенного обзора, представляется, что в настоящее время в агропродовольственном секторе наибольшие шансы стать сильными, мировыми кластерами. При выборе этих кластеров, учитываются потенциалы развития, расположенные в относительной концентрации трудоустройства и количестве субъектов в отдельных аграрно-продовольственных отраслях, а также полученными ими результатами в экспорте и нынешнее положение на фоне мировой конкуренции. Предполагается, что сильные в международном измерении аграрно-продовольственной кластеры-экспортеры могут успешно функционировать и укреплять в том случае, когда степень удовлетворения этих потребностей достаточно отличительный, чтобы поддержка в рамках политики кластеров принесло желаемые результаты.

Делая выбор ключевых кластеров экспортеров в сельскохозяйственном секторе под углом содействия их развитию в рамках государственного вмешательства, учитываются аналитическими предпосылками, указывающими на, по возможности, наиболее эффективное использование, выделяемых на эти цели средств. Эта поддержка, используемая для создания международной конкурентной позиции, должна быть направлена на укрепление наиболее слабых элементов структуры данного кластера и развитие кооперативных связей, наиболее важных для формирования цепочек создания стоимости. Существующие карты кластеров имеют характер общих организационно-структурных моделей, построенных в результате оперативного определения кластера с учетом специфики российского агропродовольственного сектора и его среды, особенно институциональной. В свою очередь, развитие кооперативных связей требует, прежде всего, активного участия всех заинтересованных сторон и должно иметь естественный характер. Участие это может быть вызваны через осознание всем заинтересованным сторонам сообщества по интересам, в чем существенную роль должны играть субъекты общественного сектора с соответствующим инструментарием политики кластеров.

Мировое потребление и производство продуктов питания вызвало приток мировых денег в сельское хозяйство, вызвав появление в России, помимо сельскохозяйственных кластеров, другого типа сельскохозяйственных предприятий - агрохолдингов. Эти предприятия приобретают существующие корпоративные фермы и вертикально интегрируют их, совмещая первичное производство, переработку, распределение, а иногда и розничные продажи. Такая вертикальная структура помогла им сократить расходы, вызванные недостатками рынка и инфраструктуры, с которыми сталкиваются российские хозяйства.

Хотя некоторые эксперты утверждают, что, наоборот, из-за большого размера агрохолдингов они страдают от эффекта масштаба, очевидно, что эти обширные, вертикально интегрированные производители имеют сильное присутствие в России, особенно в Южном округе. Например, агрохолдинги были движущей силой бурного роста птицеводства в России: с 2000 по 2013 год производство бройлеров выросло с 0,41 до 3,01 миллиона тонн. Площадь земель, принадлежащих 56 крупнейшим агрохолдингам России, увеличилась вдвое в период с 2007 по 2019 год. Федеральная служба государственной статистики (Росстат) также отмечает стабильную тенденцию в сельскохозяйственном производстве - цифры почти за тот же период [10].

Помимо сельскохозяйственных предприятий, Россия предлагает хорошую платформу для индивидуальных фермеров. Недорогая и плодородная земля страны привлекает не только российских, но и зарубежных фермеров. Несмотря на высокие барьеры для входа на рынок, позволяющие конкурировать с крупнейшими сельскохозяйственными предприятиями, как сообщила консалтинговая компания BEFL в 2019 году, избыток ресурсов и растущий спрос в России открывают многочисленные возможности для небольшой сельскохозяйственной организации. Более того, существует множество источников государственной помощи для оказания помощи местным, а также иностранным сельскохозяйственным производителям. Начиная с 2017 года, начинающие хозяйства имеют право обращаться за субсидиями, и в случае одобрения им предоставляется определенная государственная помощь. Существует также программа «Начинающий фермер», которая позволяет квалифицированным сторонам получить грант на развитие собственного сельскохозяйственного бизнеса.

Другими словами, возможности для фермеров в России растут. Таким образом, в 2016 году малому и сред- 
нему сельскому хозяйству было выдано 9200 кредитов на общую сумму 191,5 млрд. рублей [10].

С другой стороны, инфраструктура в России развита недостаточно. Кроме того, не следует забывать об отсутствии квалифицированных и добросовестных работников. Наконец, земля является одним из самых больших источников прибыли для государственных чиновников, а это означает, что если сельскохозяйственные предприятия или производители не предоставят этого, они также могут встретить препятствия на своем пути.

Доморощенные овощи готовы к переработке. Поскольку пищевая промышленность России остается очень слаборазвитой, она вынуждена импортировать большую часть своей очищенной пищи.

В условиях режима санкций России удалось достичь цели в области продовольственной безопасности, потребив лишь 20\% от всего объема производства основных продуктов кластера, что привело к необходимости увеличения экспорта. Таким образом, в 2017 году экспорт России составил 20,7 млрд. долларов, после чего президент Путин объявил о новых амбициях России: 45 млрд. долларов на экспорт продуктов питания к 2024 году.

Теперь такой рост российского аграрного сектора, несмотря на геополитические проблемы, вызывает волну интереса среди иностранных международных инвесторов, которые признают неиспользованный потенциал российского сельскохозяйственного сектора в свете текущих изменений окружающей среды. Таким образом, если в 2017 году инвестиции иностранных компаний сократились по сравнению с аналогичным периодом прошлого года, то в том же году Китай увеличил свои инвестиции в Россию в 3,5 раза по сравнению с 2016 годом. Другими словами, те, кто рассчитывает на глобальную интеграцию России в глобальная агропродовольственная цепочка может и будет извлекать выгоду, не только принося пользу своим акционерам, но и принося преимущества глобальным потребителям (например, увеличение производства продуктов питания и диверсификация глобального предложения).

Тем не менее, новые амбиции президента Путина предполагают, что ежегодный экспорт страны будет увеличиваться на $12 \%$ в год в течение следующих четырех лет. Хотя некоторые исследователи утверждают, что такая цель нереалистична, стоит отметить, что текущие экспортные показатели России довольно малы для страны с такими размерами, территорией и сельскохозяйственным потенциалом. Россия пренебрегала изобилием своих природных ресурсов (страна занимает 2-е место в мире по неэффективности с ее пахотными землями и 5-е по площади сельскохозяйственных угодий).
Кроме того, низкие урожайность сельскохозяйственных культур, а также наличие подходящих сельскохозяйственных технологий (например, парк техники и квалифицированная рабочая сила, современные складские помещения и инфраструктура).

Российское сельское хозяйство обладает огромным неиспользованным потенциалом - если только можно повысить производительность и эффективность. Большая часть сельскохозяйственной деятельности в России сосредоточена в европейской части России (до Уральских гор). Между тем на Западе очень мало известно об историческом сельскохозяйственном развитии азиатской части России, которая покрывает примерно 77\% территории России или 13 миллионов кв. км. Азиатская часть России, если брать ее отдельно, является самой большой страной на земле с большим отрывом, но в ней находится только треть обрабатываемых земель России (Росстат, 2019). Таким образом, хотя геополитические риски имеют свое негативное влияние, у международных продовольственных компаний есть множество причин для запуска новых проектов в России. Таким образом, несколько крупных иностранных компаний продолжают укреплять свои позиции в России, в том числе Louis Dreyfus, Cargill, СР Foods и NCH Capital.

Более того, что касается изменения климата, повышение температуры и экстремальные погодные явления могут увеличить площадь земель, пригодных для выращивания сельскохозяйственных культур и животноводства. Другими словами, у России есть огромный потенциал, чтобы стать лидером в области органического земледелия: 10 млн. га пахотных земель в России по-прежнему простаивают (подробнее об этом в части 3 серии). Между тем Европа уже исчерпала свои пахотные ресурсы.

Таким образом, российское правительство начало предпринимать шаги по раскрытию потенциала России в мировой индустрии. Таким образом, были объявлены основные планы по ускорению роста несырьевого экспорта и намерение поддержать этот бизнес. Кроме того, Министерство сельского хозяйства разрабатывает программы поддержки экспорта, которые будут спонсироваться государством, такие как возмещение капитальных затрат, льготное финансирование, субсидирование затрат на логистику и реализация совместных инвестиционных проектов с предприятиями. Российский экспортный центр предлагает широкий спектр услуг по продвижению российских товаров на международных рынках.

С точки зрения бизнеса, существуют благоприятные условия для развития сельскохозяйственных кластеров - производителей и экспортеров российских 
продовольственных товаров. С экологической точки зрения ресурсы, которыми располагает Россия, открывают возможности для устойчивого ведения сельского хозяйства, которые могут быть полезны для всего мира в ближайшем будущем. Хотя и то, и другое является многообещающим признаком того, что Россия в ближайшем будущем займет достойное место среди мировых поставщиков продовольствия, мы должны стремиться к достижению баланса между ними и предпочтительным акцентом на устойчивость.

\section{ВывО $\triangle \mathrm{b}$}

Конкурентоспособность отечественных экономик является результатом воздействия многих различных факторов. Выявление и оценка их значимости в конкретных экономических реалиях представляют собой задачу, с которой стремятся столкнуться как представители научного мира, так и деятели экономической политики. В течение некоторого времени считалось, что конкурентоспособность национальной и региональной экономик и входящих в их состав секторов во многом зависит от появления сильных инновационных бизнес-кластеров. Следовательно, поддержка развития этого типа кла- стеров становится парадигмой современной политики экономического развития.

Следует подчеркнуть, что эффективная реализация экономической политики, ориентированной на развитие кластеров, требует однако, продуманных действий, основанных на тщательной оценке потенциала развития кластеров и их влияния на конкурентоспособность отдельных секторов и отраслей экономики в международной торговле. Из проведенного обзора пробелов в развитии кластеров и кластерных инициатив в российском агропродовольственном секторе следует, что регионализация и распространение мер поддержки не способствуют достижению ключевой цели этой политики, как повышение конкурентоспособности, особенно, когда бенефициарами этой поддержки инициативы кластерные назначаются и функционирующие нередко в отрыве от реальных, экономически обусловленных возможностей развития кластеров. Политика поддержки развития и функционирования кластеров не может быть эффективна без опоры на рациональные предпосылки, а также потенциал развития в результате достаточного уровня концентрации экономической деятельности и выявленных преимуществ в экспорте.

1. Porter M.E., 1998a: On Competition. HBS Press, Boston.

\section{ЛИТЕРАТУРА}

2. Porter M.E., 1998b: Clusters and the New Economics of Competition. Harvard Business Review, Nov-Dee, 77-90.

3. Porter M.E., 2003: The Economic Performance of Regions. Regional Studies, 37, 549-578.

4. Porter M.E., 2008: On Competition. Updated and Expanded Edition. A Harvard Business Review Book, Boston.

5. Маршалл А. (1984). Принципы политической экономии. Т. 3; С. 257. М.: Прогресс.

6. Книпович Б.Н. (2003). К методологии районирования. М.: Издательская группа Трилобит.

7. Никонов А.А. (1995). Спираль многовековой драмы: Аграрная наука и политика России (XVIII-XXвB.). С. 298. М.: Энциклопедия российских деревень.

8. Нефедова Т.Г. (2003). Сельская Россия на перепутье. Географические очерки. С. 89. М.: Новое издательство.

9. Максимова Т.П., Рязанова 0.Е. (2015). Трансформация аграрной сферы экономики РФ: концептуальные подходы (С. 301).М.: МЭСИ.

10. Законодательное обеспечение развития переработки сельскохозяйственной продукции. 2017 год / Министерство сельского хозяйства Российской Федерации, Парламентские слушания. URL: http://www.komitet2-20.km.duma.gov.ru/upload/site2/document_news/000/111/160/MSKh_Prezentatsiya_ parlamentskie_slushaniya.pdf(дата обращения: 20.10 .2020 г.).

11. ЗАО «Облагроснаб» является дилером российских заводов по производству сельхозмашин / Аргументы и факты irk.aif.ru URL: http://www.irk.aif.ru/irk_ legend/irk_legend_details/80659 (дата обращения: 11.10 .2020 г.).

12. Зимние заботы фермеров, 23.01.2018/Аграрный портал Иркутской области. URL: http://irkagro.ru/news/1469/?sphrase_id=1352 (датаобращения: 11.10.2020 г.).

13. Интернет вещей в сельском хозяйстве. 31.07.2019 / CFORussia. URL: https://www.cfo-russia.ru/issledovaniya/index.php?article=27819 (дата 0бращения: 11.10.2020 г.).

( ) Миндлин Юрий Борисович ( mindliny@mail.ru).

Журнал «Современная наука: актуальные проблемы теории и практики» 